\title{
Localization of pNT22 70 kDa Heat Shock Cognate-like Protein in the Plasma Membrane
}

\author{
Itaru Hirai*, Noriyuki Sato, Weimin Qi, Seiji Ohtani, Toshihiko Torigoe, and Kokichi Kikuchi \\ Department of Pathology, Sapporo Medical University School of Medicine, Sapporo 060-8556, Japan
}

Key words: hsc73/cell surface expression/Triton X-114 phase separation/epitope mapping

\begin{abstract}
$A B S T R A C T$. It has been argued that $70 \mathrm{kDa}$ heat shock cognate (hsc73)-like molecules may be expressed on the surface of certain cells, but direct evidence of this has yet to be found. To clarify whether this molecule belongs to hsc73 itself, the membrane protein fraction of Daudi cells was isolated by Triton X-114 phase separation and the reactivity of this membrane protein fraction was assessed with monoclonal antibodies (mAbs) which react with $70 \mathrm{kDa}$ heat shock protein (hsp) family, i.e., NT22, A15 and 3A3. In western blotting analysis, mAb NT22-defined protein (pNT22) was clearly detected as a membrane protein of Daudi cells with an approximate molecular size of $70 \mathrm{kDa}$, whereas pNT22 was not recognized by anti-cytoplasmic hsc73/hsp 72 mAbs A15 or 3A3. By using deleted recombinant hsc73 proteins, it was determined that $\mathrm{mAb}$ NT22 recognizes the N-terminal 350-372 amino acid stretches of the hsc73 protein. mAb NT22 also reacted with the cell surface protein of Daudi cells in FACS analysis. Taken together, our present data strongly suggest that pNT22 may be a novel hsc73-like protein that is localized in the plasma membrane.
\end{abstract}

It is known that the heat shock proteins (hsp) act as molecular chaperones in various intracellular compartments $(4,10,11,13,19)$. Although these proteins do not have the known transmembrane portion in their primary amino acid structures, several studies have suggested that certain molecular chaperones, such as hsp60 (17), hsp70 $(20,24,25,26)$ and hsp90 (22), are expressed on the cell surface. We reported previously that a mAb \#067-defined $70 \mathrm{kDa}$ protein can be expressed on the cell surface of rat fibroblast transformed by ras-oncogene. This protein was recognized by anti-rat hsc73 $\mathrm{mAb}$, and its expression was enhanced by treatment of cells with heat and other physical and chemical stresses, implying that mAb \#067defined antigen may belong to the $70 \mathrm{kDa}$ hsp family (25). Furthermore, it was suggested that they may play the role of an antigen-presenting molecule to $\mathrm{CD}^{-}$, $\mathrm{CD}^{-}$, double negative (DN) $\mathrm{T}$ cells $(24,25)$. This notion is intriguing since it indicates a very novel presentation mechanism. However, it is not known so far how and which subfamily of $70 \mathrm{kDa}$ hsp could be expressed on the cell surface. Since no known mammalian $70 \mathrm{kDa}$ hsp with the hydrophobic transmembrane portion has

\footnotetext{
* To whom correspondence should be addressed.

Tel: +81-11-611-2111, Fax: +81-11-643-2310

E-mail: hiraii@sapmed.ac.jp

Abbreviations: hsc, heat shock cognate protein; mAb, monoclonal antibody; hsp, heat shock protein; DNT cell, double negative T cell; TTX-114, Triton X-114; IPTG, isopropyl $\beta$-D-thiogalactpyranoside; GPI, glycosyl phosphatidyl inositol.
}

been ever reported, there is a possibility that a new member of the $70 \mathrm{kDa} h s p$ family with such a portion is localized in the plasma membrane.

Meanwhile, we have previously reported that antihsc73 specific mAb NT22 could also detect the cell surface molecule expressed on EBV-transformed B cell lines, such as Daudi and Raji cells, and that the expression of this molecule was also enhanced by several stressors, such as heat, arsenic acid and L-azetidine-2carboxilic acid (26). In the current investigation, we used mAb NT22 and the newly-developed anti-cytoplasmic hsc73/hsp $72 \mathrm{mAb} A 15$, and assessed the interaction between these mAbs and membrane proteins prepared with Triton X-114 (TTX-114). The data implied that mAb NT22-defined (pNT22) antigen, but not $\mathrm{mAb}$ A15-defined antigen, is localized in the plasma membrane, strongly suggesting that a novel hsc73-like protein is being expressed on the cell surface.

\section{MATERIALS AND METHOD}

Cells and Antibodies

Daudi Burkitt's lymphoma cells were cultured in Dulbecco's modified MEM supplemented with 10\% fetal calf serum and 2 $\mathrm{mM}$ of L-glutamine. Anti-hsc73 mAb NT22 with IgM isotype was described earlier (26). Mouse mAbs against cytoplasmic hsc $73 / \mathrm{hsp} 72$ were obtained following methods described elsewhere (27). Briefly, hsc73/hsp72-containing ATP-binding proteins were used to immunize mice. Splenic lymphocytes of these mice were fused with NS-1 myeloma cells and mAbs 
Table I. EPITOPE MAPPING OF ANTI HSP 72/HSC73 mAbs.

\begin{tabular}{cc}
\hline Antibody & Epitope* $^{*}$ \\
\hline NT22 & $350-372$ \\
A15 & $541-630$ \\
3A3 & $373-540$ \\
\hline$*$ Epitope is indicated by the number of amino acids \\
of human hsc73.
\end{tabular}

were obtained. After limiting dilution, mAb A15 with IgM isotype was selected. In the present study, we also used antihsc73/hsp72 mAbs, i.e., 3A3, 5A5 and 2A4 (Affinity Bioreagents, Neshanic Station, NJ USA). It was shown that 5A5, 2A4, and A15 mAbs react with cytoplasmic hsc73/hsp72. Anti-hsp40 polyclonal antibody was obtained from a rabbit immunized with recombinant human hsp40. Anti-CD20 $\mathrm{mAb}$ TB2-2B3 was described elsewhere (16).

\section{Construction of hsc73 deletion constructs and epitope map-} ping of $\mathbf{m A b s}$

The plasmid pETHSC70, encoding human hsc73 (9), was a kind gift from Dr. Sue Fox (Northwestern University, Evanston, IL USA). To prepare the deletion constructs, i.e., pET $\Delta S$, pET $\Delta E$, pET $\Delta H L, p E T \Delta H S$, pETSBDce and pETSBDpe, the pETHSC70 vector was double digested by XbaI-SacI, XbaI-EcoRI, XbaI-HindIII, XbaI-HindIII, HincII-EcoRI and PvuII-EcoRI. The fragments were inserted into pET21 vector (Novagen, Madison, WI USA).

The constructs were transformed into $E$. coli BL21 (DE3). Bacterial transformants were grown at $37^{\circ} \mathrm{C}$. Recombinant deletion proteins were induced with $1 \mathrm{mM}$ of isopropyl $\beta$-Dthiogalactopyranoside (IPTG) at $37^{\circ} \mathrm{C}$ for 2 hours. The IPTG-induced bacterial cell extracts were used for epitope mapping of mAbs.

\section{FACS analysis}

FACS analysis for detection of the cell surface antigens was described earlier (26). The normal mouse IgM (DAKO; A/S, Denmark) was used as a negative control in FACS analysis.

\section{Phase separation of membrane proteins with Triton X-114} and western blotting analysis

The membrane fraction was prepared by the method described in Bordier (3) with some modifications as illustrated in Fig. 1. $1 \times 10^{7}$ Daudi cells were washed twice with PBS. The cells were lysed in $1 \mathrm{ml}$ of 1\% TTX-114, $10 \mathrm{mM}$ Tris-HCl, 250 $\mathrm{mM} \mathrm{NaCl}, \mathrm{pH}$ 8.0. The cell lysate was separated from the cell debris by centrifugation at $14,500 \mathrm{rpm}$ for $30 \mathrm{~min}$ at $4^{\circ} \mathrm{C} \mathrm{((a)}$ in Fig. 1). The supernatant was incubated at $37^{\circ} \mathrm{C}$ for $5 \mathrm{~min}$ and centrifuged at $10,000 \mathrm{rpm}$ at room temperature for $5 \mathrm{~min}$. By this incubation and centrifugation, the cell lysate became cloudy (b) and the detergent phase was found as an oily layer at the bottom of the tube (c). The upper aqueous phase (f), which contained water-soluble cytoplasmic proteins, was stored for the analysis. The detergent phase (d), which con-

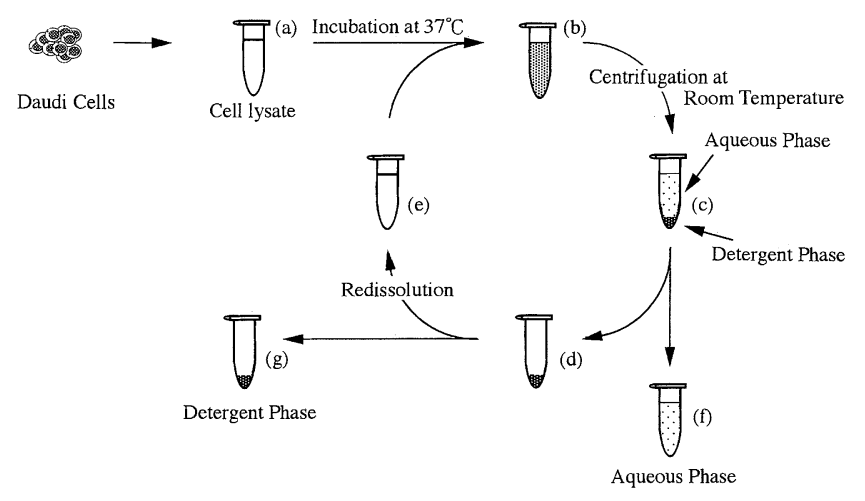

Fig. 1. Procedure of phase separation of membrane proteins using Triton X-114. The cell lysate prepared with Triton X-114 is incubated at $37^{\circ} \mathrm{C}$ (a). This incubation makes the lysate cloudy (b). After centrifugation, the lysate is separated into the aqueous and the detergent phases which contain the cytoplasmic proteins and the amphiphilic membrane proteins, respectively (c). After two more similar rounds $(b-e)$ of phase separation of membrane proteins, the consequent aqueous (f) and detergent phase preparations (g) were used for the analysis.

tained integral membrane proteins, was dissoluted in $0.9 \mathrm{ml}$ of $10 \mathrm{mM}$ Tris- $\mathrm{HCl}, 250 \mathrm{mM} \mathrm{NaCl}, \mathrm{pH} 8.0$ (e), and the phase separation was repeated to exclude the remaining cytoplasmic proteins. After two more rounds of the phase separation, the detergent phase $(\mathrm{g})$ and the stored aqueous phase were analyzed by western blotting analysis as described elsewhere (26).

\section{RESULTS}

Production of deleted hsc73 proteins and epitope mapping of anti hsc73/hsp72 antibodies

To characterize the epitope location of anti-hsc73 specific mAb NT22 and the newly-developed anti-cytoplasmic hsc73/hsp72 specific mAb A15, a series of deleted hsc73 proteins were produced as shown in Fig. 2. Using these deleted hsc73 proteins, the epitope mapping was carried out. $E$. coli lysates containing deleted hsc73 proteins were run on SDS-PAGE and western blotted proteins were detected by mAbs NT22, A15 and 3A3. As shown in Fig. 3a and Fig. 3b, mAb NT22 could detect wild type hsc73, $\Delta \mathrm{S}, \Delta \mathrm{E}$ and SBDce, and $\mathrm{mAb}$ A15 reacted with hsc73 and $\Delta S$, respectively. It appeared that A15 also very weakly reacted with molecules of approximately $40 \mathrm{kDa}$ in molecular size. However, $\Delta \mathrm{E}$ was not detected with $\mathrm{mAb} \mathrm{A} 15$, suggesting that the epitope sequence of $\mathrm{mAb} A 15$ was not included in $\Delta \mathrm{E}, \Delta \mathrm{HL}, \Delta \mathrm{HS}$, SBDce, and SBDpe. Therefore, we supposed that such weak reactivities of $\mathrm{mAb}$ A15 were nonspecific. In contrast, it appeared that $\mathrm{mAb} 3 \mathrm{~A} 3$ could widely react with deleted hsc73 proteins, such as hsc73, $\Delta \mathrm{S}, \Delta \mathrm{E}$, SBDce and SBDpe, although nonspecific binding of $\mathrm{mAbs}$ to $E$. coli protein 


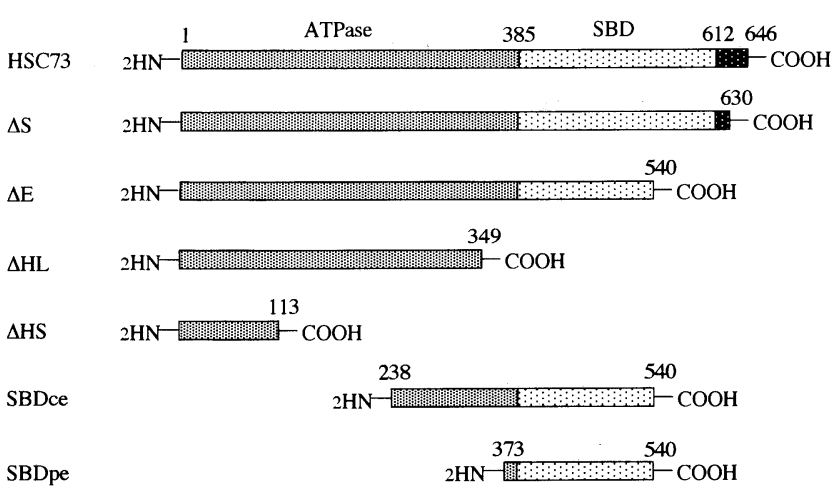

Fig. 2. The deletion constructs of hsc73. These constructs encoding deleted recombinant hsc 73 proteins were produced by double digestions at certain endonuclease sites of human hsc73 gene and insertion into pET 21 expression vector. The deleted hsc 73 proteins and their retained amino acids were indicated.

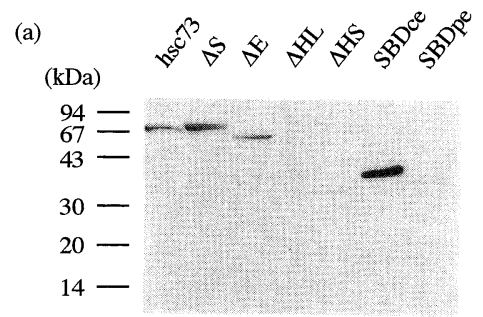

(b)

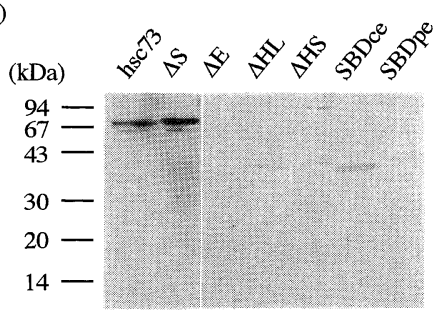

(c)

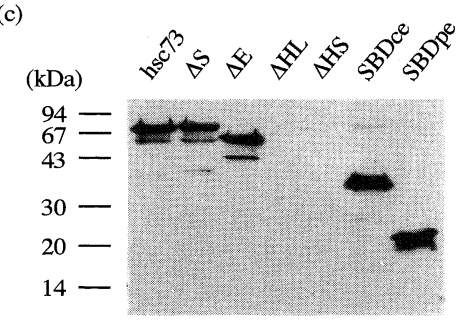

Fig. 3. The epitope mapping of mAbs NT22, A15 and 3A3. The series of deletion constructs were transformed into $E$. coli BL21 (DE3). The transformants were grown at $37^{\circ} \mathrm{C}$ and recombinant deleted hsc73 proteins were induced with $1 \mathrm{mM}$ IPTG for 2 hours at $37^{\circ} \mathrm{C}$. E. coli cell extracts containing deleted hsc 73 proteins (extract preparations of $10^{7}$ cells/lane) were run on SDS-PAGE and western blotted proteins were detected by mAbs NT22 (a), A15 (b) and 3A3 (c). or reactivity with possible proteolytic fragments of recombinant proteins was observed (Fig. 3c). As summarized in Table. I, these results indicated that the epitopes of mAb NT22 and mAb A15 were located in Nterminal 350-372 and 541-630 amino acids of hsc73, respectively. It was also shown that $\mathrm{mAb} 3 \mathrm{~A} 3$-defined epitope was located in N-terminal 373-540. This is reasonable since it was identified that the epitope of $\mathrm{mAb} 3 \mathrm{~A} 3$ is localized in N-terminal $504-617$ as previous reported (9).

\section{Reaction of anti-hsc73/hsp $72 \mathrm{mAbs}$ with the cell sur- face antigens}

To confirm whether these mAbs could detect the antigens expressed on the cell surface, we used live Daudi cells in FACS analysis. As shown in Fig. 4, mAb NT22, but not anti-cytoplasmic hsc73/hsp72 mAb A15 or $\mathrm{mAb} 3 \mathrm{~A} 3$, could react with the cell surface molecule expressed on Daudi cells. These observations suggested that an NT22-defined pNT22 protein was expressed on the cell surface.

mAb reactivity of membrane proteins using phase separation with Triton $\mathrm{X}-114$

To further assess whether pNT22 could be localized in the membrane fraction, we used the phase separation method in preparation of membrane proteins of Daudi cells with TTX-114. Namely, hydrophilic proteins were excluded in the aqueous phase, and amphiphilic integral membrane proteins were recovered in the detergent phase. We used the aqueous phase as the cytoplas-

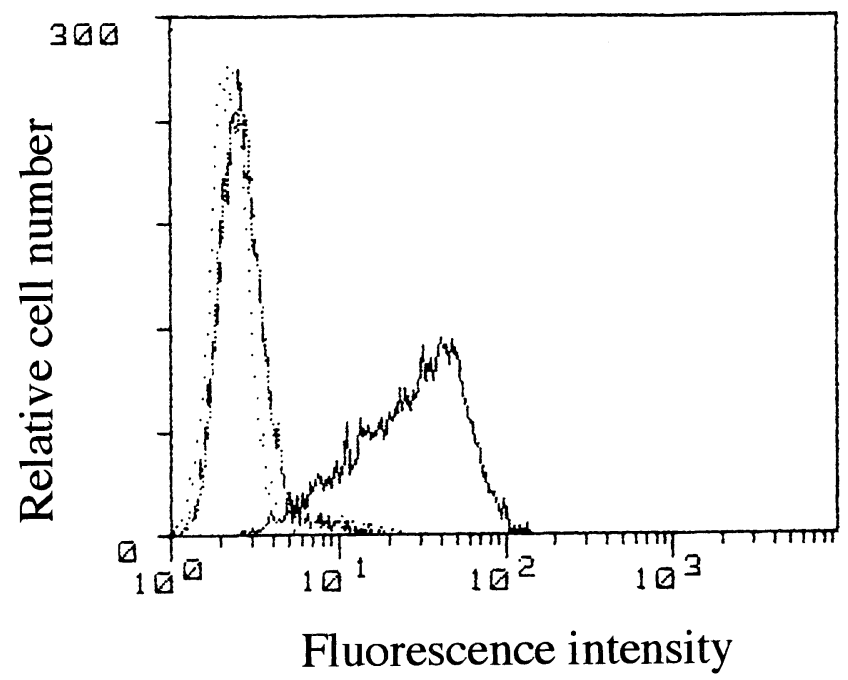

Fig. 4. FACS profile of Daudi cell. Daudi cells were stained by a saturated amount of mAbs NT22(-), A15(--) or 3A3 (…). A saturated amount of normal mouse IgM (DAKO; A/S, Denmark) was used as negative control. Goat anti-mouse $\operatorname{Ig}(\mathrm{G}+\mathrm{M})$ conjugated with FITC was then reacted and analyzed by FACS. 

(a)
(b)
(c)
(d)
(e)

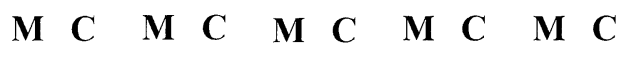

(kDa)
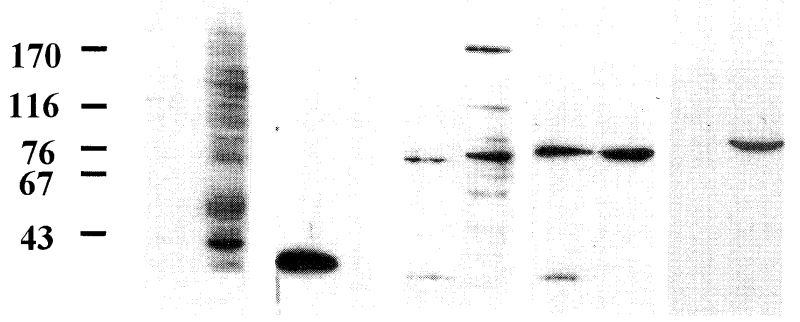

Fig. 5. Western blot analysis of phase separated Daudi cell lysate. The aliquots of the aqueous (C; cytoplasmic protein fraction) and detergent phase (M; membrane protein fraction) preparations lysate preparations of $10^{5}$ cells/lane) were run on SDS-PAGE. Both of the phases were detected by anti-hsp40 polyclonal antibody (a), antiCD20 mAb L26 (b), mAb NT22 (c), mAb 3A3 (d) and mAb A15 (e).

mic protein fraction and the detergent phase as the whole membrane protein fraction for further analysis. After phase separation, aliquots of both fractions were analyzed by SDS-PAGE and western blotting.

We first assessed the separation efficiency of cytoplasmic and membrane proteins with TTX-114. As shown in Fig. 5, a polyclonal anti-hsp40 antibody detected multiple bands of hsp40, presumably complexed with various kinds of substrate, exclusively in the cytoplasmic protein fraction, while one of CD20, a typical membrane protein, was stained only in the membrane protein fraction, indicating that this phase separation for cytoplasmic and membrane proteins was very strictly done. By using the same samples, it was clearly shown that mAb NT22 and mAb 3A3 reacted to molecules of approximately $70 \mathrm{kDa}$ in molecular size in the membrane protein fraction, as well as cytoplasmic hsc73/hsp72. NT22 also reacted with multiple proteins of various molecular sizes in the cytoplasmic fraction. Furthermore, NT22 and 3A3 could also detect a band with approximately $30 \mathrm{kDa}$ in molecular size from membrane fraction, but, this seemed to be a nonspecific reaction or degradation protein product, since it was not detected in Fig. 6. In contrast, mAb A15 only stained cytoplasmic hsc73/hsp72. Moreover, to exclude the possibility that the molecule detected by $\mathrm{mAb}$ NT22 in the detergent phase was contaminated from cytoplasmic hsc73/hsp72, we assessed whether pNT22 could be detected by conventional anti-cytoplasmic hsc73/hsp72 antibodies. As shown in Fig. 6, the band corresponding to pNT22 was not detected by anticytoplasmic hsc $73 / \mathrm{hsp} 72 \mathrm{mAbs}$ such as $5 \mathrm{~A} 5,2 \mathrm{~A} 4$, and A15. These data indicated that pNT22 was not cytoplasmic hsc73 itself. Furthermore, it is noteworthy that pNT22 had a smaller molecular weight than mAb 3A3-
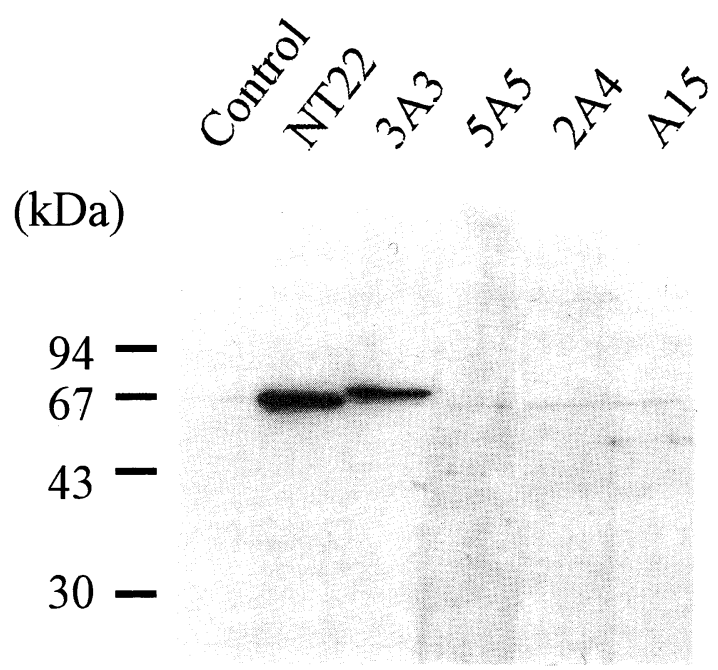

Fig. 6. Western blot analysis of pNT22 by anti-hsc73/hsp 72 mAbs. The detergent phase preparation of Daudi cell lysate (lysate preparations of $10^{5}$ cells/lane) was run on SDS-PAGE, and detected in western blotting by mAbs NT22, 3A3, 5A5, 2A4 and A15.

defined molecule (p3A3), suggesting that pNT22 was distinct from p3A3. The FACS profile indicates that pNT22 might be a hsc73-like novel membrane protein.

\section{DISCUSSION}

Recent reports have suggested that certain cells express hsp, such as hsp60, hsp70, and hsp90 on the cell surface $(17,20,22,24,25,26)$. We reported previously that an hsp70-like molecule could express itself on the cell surface, suggesting that such molecules may act as the antigen-presenting molecules to $\mathrm{CD}^{+}, \mathrm{CD}^{-}$, CD8 ${ }^{-}$, NKR-P1- DNT cells $(24,25)$. However, no known mammalian hsp70 with the hydrophobic transmembrane region has been reported so far. Therefore, it is possible that a new member of hsp 70 with a transmembrane region is localized in the plasma membrane. In the current investigation, we suggested that the mAb NT22-defined antigen, pNT22, might be localized in the plasma membrane. In conjunction with our previous data, it is highly likely that pNT22 is an hsc73related novel membrane protein.

To resolve the problem of whether the cell surfaceexpressed pNT22 belongs to conventional cytoplasmic hsc73 itself, we adopted the phase separation technique using Triton X-114 to prepare the membrane fraction of Daudi cells (3). By this separation, integral membrane proteins were efficiently recovered in the detergent phase. Indeed, cytoplasmic HSP40 appeared to be exclusively stained in the aqueous phase, whereas CD20, a typical membrane protein, was only stained in the detergent phase. This indicated that the phase sepa- 
ration was very strictly performed, and that the detergent phase contained almost pure membrane proteins. Using this membrane protein fraction, we carried out western blotting analysis with anti-hsc73/hsp $72 \mathrm{mAbs}$. The results showed that $\mathrm{mAb}$ NT22 reacted to approximately $70 \mathrm{kDa}$ protein pNT22 in the membrane protein fraction as well as in the cytoplasmic protein fraction. There was still a possibility that pNT22 in the membrane protein fraction was contaminated by cytoplasmic hsc73, because hsc73 is amply expressed in the cytoplasm. To eliminate this possibility, we employed mAbs that react with conventional cytoplasmic hsc73/hsp72. Namely, if pNT22 was a contaminated cytoplasmic hsc73, anti cytoplasmic hsc73/hsp72 mAbs should detect the molecule even in the detergent phase. However, pNT22 was not detected by these antibodies, indicating that pNT22 in the membrane fraction was not a contamination of cytoplasmic hsc73, but was localized in the membrane fraction. It was also interesting that the molecular size of pNT22 was different from that of $\mathrm{p} 3 \mathrm{~A} 3$ in the membrane fraction. This may imply that pNT22 is a novel hsc73-like membrane protein.

It should be noted that the detergent phase contained proteins of all cellular membranes such as plasma membrane, mitochondrial membranes or endoplasmic reticulum and Golgi apparatus. However, FACS analysis showed that pNT22 was stained on the cell surface. This means that pNT22 is at least localized on the plasma membrane. On the other hand, FACS analysis indicated that p3A3 was not detected on the cell surface. These results imply two possibilities: 1 ) that p3A3 is localized in the intracellular membrane portion such as mitochondrial membranes or endoplasmic reticulum; and 2) that p3A3 is localized on the plasma membrane, but that the mAb 3A3-defined epitope is not exposed to the cell surface. Consequently, we could not identify p3A3 as a cell-surface localized membrane protein.

Meanwhile, the results of epitope mapping using deleted hsc 73 proteins showed that the epitope defined by NT22 was located in N-terminal 350-372 of hsc73. This region of hsc73 is highly conserved among the hsp70 family proteins of different species (2) such as metazoan (12), yeast (5), Drosophila (15), plants (18) and mammals $(1,6,8,14,21)$. Indeed, a homology search with this epitope sequence from the available computer database showed that no other molecules than the hsp70 family, including hsc73, hsp72, BiP and mitochondrial hsp75, were picked up. One could not exclude the possibility that pNT22 is a non hsc73-related membrane protein which contains the above sequence. However, as reported previously (26), pNT22 expression is enhanced by several stress treatments. Therefore, it is highly likely that the protein containing this sequence belongs to the hsp70 family. Thus, it may be hypothesized that pNT22 is a new member of the hsp70 family with a plasma membrane localized form.

Finally, the biological function and genetic structure of pNT22 has not been identified so far. However, the fact that pNT22 was exclusively recovered in the detergent phase suggested that pNT22 was localized on the plasma membrane either as an integral membrane protein, or as a glycosyl phosphatidyl inositol (GPI)anchored protein (7) or as a protein associated with a distinct transmembrane protein. Our preliminary studies excluded the possibility that pNT22 was a GPIanchored protein, because phospholipase $\mathrm{C}$ treatment of cells did not influence the cell surface expression of pNT22. Meanwhile, there is the possibility that pNT22 may associate with a distinct transmembrane protein as a resident molecular chaperone in the plasma membrane or as a transporter of some antigenic peptides from intracellular to extracellular spaces (23). Indeed, our previous studies suggested that mAb \#067 definedrat hsc73-like protein acted as an antigen presenting molecule on the cell membrane and interacted with $\mathrm{CD}^{+}, \mathrm{CD}^{-}{ }^{-}, \mathrm{CD}^{-}$DNT cytotoxic cells $(24,25)$. One could expect pNT22 to act similar to an mAb \#067defined protein. However, since NT22 could not make immunoprecipitates, it is not clear whether pNT22 is the same as 067-defined molecules. We are now undertaking an identification of a gene encoding pNT22. Through this molecular cloning, the biological function and the cell surface expression mechanism should be totally explained.

\section{REFERENCE}

1. Bhattacharyya, T., Karnezis, A.N., Murphy, S.P., Hoang, T., Freeman, B.C., Phillips, B., and Morimoto, R.I. 1995. Cloning and subcellular localization of human mitochondrial hsp70. J. Biol. Chem., 270: 1705-1710.

2. Boorstein, W.R., Ziegelhoffer, T., and Craig, E.A. 1994. Molecular evolution of the HSP70 multigene family. J. Mol. Evol., 38: 1-17.

3. BoRDIER, C. 1981. Phase separation of integral membrane proteins in Triton X-114 solution. J. Biol Chem., 256: 1604-1607.

4. BuCHNER, J. 1996. Supervising the fold: functional principles of molecular chaperones. FASEB J., 10: 10-19.

5. Craig, E.A., BaXter, B.K., Becker, J., Halladay, J., and ZIEGELHOFFER, T. 1994. Cytosolic hsp70 of Saccharomyces cerevisiae: roles in protein synthesis, protein translocation, proteolysis, and regulation. In "The Biology of Heat Shock Proteins and Molecular Chaperones." (R.I. Morimoto, A. Tissieres and C. Georgopoulos, Eds.), Cold Spring Harbor Press, Cold Spring Harbor, NY.

6. DworniczaK, B. and Mirault, M.E. 1987. Structure and expression of a human gene coding for a $71 \mathrm{kd}$ heat shock 'cognate' protein. Nucleic Acids Res., 15: 5181-5197.

7. ENGLUND, P.T. 1993. The structure and biosynthesis of glycosyl phosphatidylinositol protein anchors. Annu. Rev. Biochem., 62: 121-138. 
8. Fathallah, D.M., Chelif, D., Dellagi, K., and Arnaout, M.A. 1993. Molecular cloning of a novel human hsp70 from a B cell line and its assignment to chromosome 5. J. Immunol., 151: $810-813$.

9. Freeman, B.C., Myers, M., P., Schumacher, R., and MoRimoto, R.I. 1995. Identification of a regulatory motif in hsp70 that affects ATPase activity, substrate binding and interaction with HDJ-1. EMBO J., 14: 2281-2292.

10. Frydman, J. and Höhfeld, J. 1997. Chaperones get in touch: the Hip-Hop connection. Trends Biochem. Sci., 22: 87-92.

11. HaRTL, F.U. 1996. Molecular chaperones in cellular protein folding. Nature, 381: 571-580.

12. Hedstrom, R., Culpepper, J., Harrison, R.A., Adabian, N., and NewPoRT, G. 1987. A major immunogen in Schistoma mansoni infections is homologous to the heat-shock protein hsp70. J. Exp. Med., 165: 1430-1435.

13. Hightower, L.E., SAdis, S.E., and TAKenaKa, I.M. 1994. Interactions of vertebrate hsc70 and hsp70 with unfold proteins and peptides. In "The Biology of Heat Shock Proteins and Molecular Chaperones." (R.I. Morimoto, A. Tissieres and C. Georgopoulos, Eds.), Cold Spring Harbor Press, Cold Spring Harbor, NY.

14. Hunt, C. and Morimoto, R.I. 1985. Conserved features of eukaryotic hsp70 genes revealed by comparison with the nucleotide sequence of human hsp70. Proc. Natl. Acad. Sci. USA., 82: $6455-6459$.

15. Ingolia, T.D., Graig, E.A., and McCarthy, B.J. 1980. Sequence of three copies of the gene for the major Drosophila heat shock induced protein and their flanking regions. Cell, 21: 669679.

16. Ishit, I., TAJami, T., Yuasa, H., TaKeI, T., and KiKUChI, K. 1984. Two distinct systems in human B lymphocytes: identification of cell surface and intracellular antigens using monoclonal antibodies. Clin. Exp. Immunol., 58: 183-192.

17. Kaur, I., Voss, S.D., Gupta, R.S., Schell, K., Fisch, P., and SONDEL, P.M. 1993. Human Peripheral $\gamma \delta$ T cells recognize hsp60 molecules on Daudi Burkitt's lymphoma cells. J. Immunol., 150: 2046-2055.

18. LiN, T.Y., Duck, N.B., Winter, J., and FolK, W.R. 1991. Sequence of two hsc70 cDNAs from Lycopersicon esculentum. Plant Mol. Biol., 16: 475-478.
19. Melnick, J. and Argon, Y. 1995. Molecular chaperones and the biosynthesis of antigen receptors. Immunol. Today., 16: 243-250.

20. Multhoff, G., Botzler, C., Jennen, L., Schmidt, J., Ellwart, J., and Issels, R. 1997. Heat shock protein 72 on tumor cells. I. Immunol., 158: 4341-4350.

21. Munro, S. and Pelham, R.B. 1986. An hsp70-like protein in the ER: identity with the $78 \mathrm{kd}$ glucose-regulated protein and immunoglobulin heavy chain binding protein. Cell, 46: 291300.

22. Srivastava, P., K., Udono, H., Blachere, N., E., and Li, Z. 1994. Heat shock proteins transfer peptides during antigen processing and CTL priming. Immunogenetics, 39: 93-98.

23. Suto, R. and SRIvastava, P.K. 1995. A mechanism for the specific immunogenicity of heat shock protein-chaperoned peptides. Science, 269: 1585-1588.

24. Takashima, S., Sato, N., Kishi, A., Tamura, Y., Hirai, I., Torigoe, T., Yagihashi, A., Takahashi, S., SAGae, S., Kudo, R., and KIKUCHI, K. 1996. Involvement of peptide antigens in the cytotoxicity between $70-\mathrm{kDa}$ heat shock cognate proteinlike molecule and $\mathrm{CD}^{+}, \mathrm{CD} 4^{-}, \mathrm{CD} 8^{-}, \mathrm{TCR} \alpha \beta^{-}$killer T cells. J. Immunol., 157: 3391-3395.

25. Tamura, Y., Tsuboi, N., Sato, N., and KikUChI, K. 1993. 70$\mathrm{kDa}$ heat shock cognate protein is a transformation-associated antigen and a possible target for the host's anti-tumor immunity. J. Immunol., 151: 5516-5524.

26. Tsuboi, N., Ishikawa, M., Tamura, Y., Takayama, S., Tobioka, H., Matsuura, A., Hirayoshi, K., Nagata, K., Sato, N., and KIKUCHI, K. 1994. Monoclonal antibody specifically reacting against 73-kilodalton heat shock protein: possible expression on mammalian cell surface. Hybridoma, 13: 373381.

27. Yagihashi, A., Sato, N., Torigoe, T., Okubo, M., Konno, A., Takahashi, N., Yamashita, T., Fujinaga, K., Kuzumaki, N., and KIKUCHI, K. 1988. Identification of the transformationassociated cell surface antigen expressed on the rat fetus derived fibroblast. Cancer Res., 48: 2798-2804.

(Received for publication, March 16, 1998

and in revised form, April 23, 1998) 